\title{
Tomografia computadorizada de mastocitomas em cães: avaliação pré e pós-tratamento quimioterápico ${ }^{1}$
}

\author{
Carla A.B. Lorigados ${ }^{2 *}$, Julia Maria Matera², Antonio A. Coppi ${ }^{3}$, Thaís R. Macedo ${ }^{4}$, \\ Fernando V.L. Ladd ${ }^{3}$, Vanessa A.F. de Souza ${ }^{5}$ e Ana Carolina B.C.F. Pinto ${ }^{2}$
}

\begin{abstract}
Lorigados C.A.B., Matera J.M., Coppi A.A., Macedo T.R., Ladd F.V.L., Souza V. A.F. \& Pinto A.C.B.C.F. 2013. [Computed tomography of mast cell tumors in dogs: assessment before and after chemotherapy.] Tomografia computadorizada de mastocitomas em cães: avaliação pré e pós-tratamento quimioterápico. Pesquisa Veterinária Brasileira 33(11):1349-1356. Departamento de Cirurgia, Faculdade de Medicina Veterinária e Zootecnia da Universidade de São Paulo, Av. Prof. Dr. Orlando Marques de Paiva 87 Cidade Universitária, São Paulo, SP 05508- 2701, Brazil. E-mail: clorigados@usp.br

Nineteen dogs with mast cell tumors treated with chemotherapy were evaluated by computed tomography (CT). Were evaluated aspects related to contours, attenuation, postcontrast enhancement and presence of cleavage with adjacent structures. The RECIST criteria and volumetric measurement of lesions were performed to assess the response to treatment. The mast cell tumors presented a homogeneous or heterogeneous attenuation, presented more frequently a well delineated and regular contours and moderate enhancement after intravenous administration of the iodinated contrast media. The methods RECIST and volumetric measurements showed an excellent agreement to the classification of therapeutic response, providing a good parameter of the response to treatment. The CT examination proved to be useful in the delimitation of the tumor and an important tool for planning of surgical margins.
\end{abstract}

INDEX TERMS: Mast cell tumor, computed tomography, measure, volume, dogs.

RESUMO.- Foram avaliados, por meio da tomografia computadorizada, 19 cães com mastocitomas tratados com quimioterapia. Aspectos como contorno, atenuação, realce pós-contraste e presença de clivagem com estruturas adjacentes foram avaliados. Aplicaram-se os critérios RECIST e a mensuração volumétrica das lesões para se avaliar a resposta ao tratamento. Quanto à atenuação, os mastocitomas se mostraram como lesões homogêneas ou heterogêneas, com tendência a limites definidos e contornos regulares

\footnotetext{
' Recebido em 15 de abril de 2013.

Aceito para publicação em 30 de outubro de 2013.

${ }^{2}$ Docente do Departamento de Cirurgia, Faculdade de Medicina Veterinária e Zootecnia (FMVZ), Universidade de São Paulo (USP), Av. Prof. Dr. Orlando Marques de Paiva 87, Cidade Universitária, São Paulo, SP 055082706, Brasil. *Autor para correspondência: clorigados@usp.br

${ }^{3}$ Laboratório de Estereologia Estocástica e Anatomia Química (LSSCA), Departamento de Cirurgia, Faculdade de Medicina Veterinária e Zootecnia, USP, São Paulo, SP.

${ }^{4}$ Doutoranda do Departamento de Cirurgia, FMVZ-USP, São Paulo, SP.

${ }^{5}$ Doutoranda do Departamento de Medicina Veterinária Preventiva e Saúde Animal, FMVZ-USP, e Docente do Curso de Medicina Veterinária das Faculdades Metropolitanas Unidas (FMU), São Paulo, SP.
}

e apresentaram realce moderado após administração do contraste iodado intravenoso. Os métodos RECIST e a mensuração volumétrica apresentaram uma excelente concordância na classificação da resposta terapêutica, fornecendo um bom parâmetro da resposta ao tratamento instituído. 0 exame de tomografia computadorizada se mostrou útil na delimitação do tumor e importante ferramenta no planejamento das margens cirúrgicas.

TERMOS DE INDEXAÇÃO: Mastocitoma, tomografia computadorizada, mensuração, volume, cão.

\section{INTRODUÇÃO}

O diagnóstico por imagem tem assumido um importante papel na clínica oncológica, sendo utilizado não somente no diagnóstico, mas também no estadiamento, monitoramento ou auxiliando no planejamento do tratamento, seja ele cirúrgico, quimioterápico ou radioterápico das neoplasias.

Na medicina, com a finalidade de se avaliar a resposta terapêutica dos tumores submetidos à quimioterapia, o RECIST (Response Evaluation Criteria in Solid Tumors) tem sido 
amplamente utilizado. A partir das imagens tomográficas em corte transversal, o critério se baseia na mensuração unidimensional da lesão no seu maior diâmetro. 0 RECIST tem classificado a doença em quatro categorias: remissão completa (RC), remissão parcial (RP), doença estável (DE) e doença progressiva (DP). A RC é caracterizada quando as lesões desapareceram completamente, a RP quando ocorre a diminuição de pelo menos $30 \%$ do maior diâmetro da lesão, a DE quando os critérios não se enquadram nem em RP e nem em DP e DP quando há aumento de pelo menos $20 \%$ do maior diâmetro do tumor e/ou aparecimento de novas lesões (Suzuki et al. 2008, Mariotti 2009, Stacchiotti et al. 2009, D’ippolito et al. 2011).

Com a introdução de novos softwares de reconstrução de imagens multiplanares e 3D, as mensurações volumétricas dos tumores passaram a ser consideradas na avaliação da resposta terapêutica. Poucos artigos comparam as duas formas de mensuração, unidimensional e volumétrica (Hopper et al. 1996, Sohaib et al. 2000), restringindo-se a lesões mais regulares. Sohaib et al. (2000) afirmam que há certa limitação na acurácia e reprodutibilidade do método para lesões pequenas. Para determinados cortes e pitch, o efeito de volume parcial é maior para estruturas menores e o erro na mensuração dessas estruturas é maior. Quando mensurações volumétricas são utilizadas, um aumento maior que $40 \%$ do volume das lesões é considerado como doença progressiva e uma redução de pelo menos 65\%, resposta parcial (Sohaib et al. 2000).

A derme e o subcutâneo são localizações muito comuns de neoplasias em cães (Merlo et al. 2008). Dessas neoplasias, o mastocitoma tem sido descrito como um dos tumores mais frequentes (Rothwell et al. 1987, Dobson et al. 2002, Bronden et al. 2010).

0 tratamento dos mastocitomas representa um desafio, devido seu comportamento biológico ser extremamente variável. Muitos fatores estão envolvidos no seu prognóstico, como a localização (Sfiligoi et al. 2005, Welle et al. 2008), margem cirúrgica (Michels et al. 2002, Simpson et al. 2004), atividade mitótica (Elston et al. 2009), grau histológico (Macy, 1986), estadiamento (Thamm \& Vail 2007), alguns marcadores moleculares, como Ki-67, PCNA, AgNOR (Scase et al. 2006, Maglennon et al. 2008), a expressão KIT pelos mastócitos (Thompson et al. 2011) e a densidade vascular da lesão (Preziosi et al. 2004).

Diante deste panorama, este estudo avaliou a contribuição da tomografia computadorizada na análise de cães acometidos por mastocitoma e submetidos ao tratamento quimioterápico.

\section{MATERIAL E MÉTODOS}

Foram avaliados 19 cães, machos e fêmeas, de raças variadas, com diagnóstico histopatológico de mastocitoma grau II, segundo classificação de Patnaik et al. (1984). Os exames histológicos foram realizados a partir de amostras dos tumores colhidas por biópsia com punch de $8 \mathrm{~mm}$ de diâmetro. Os cães inclusos neste estudo não apresentavam evidências de metástase à distância segundo o exame radiográfico do tórax e a ultrassonografia abdominal e foram submetidos exclusivamente à quimioterapia na primeira etapa do tratamento.
O exame tomográfico dos mastocitomas foi realizado em equipamento de tomografia computadorizada helicoidal ${ }^{6}$, com uma única fileira de detectores. A técnica utilizada foi $120 \mathrm{kVp}$ e $150 \mathrm{~mA}$ e as imagens obtidas com filtros para tecidos moles e ósseo. Os animais foram posicionados sobre a mesa tomográfica em decúbito dorsal ou esternal, na dependência da localização da neoplasia. Foram obtidos cortes no plano transversal e a espessura e incremento variou dependendo das dimensões de cada formação. As imagens tomográficas foram obtidas antes e após a administração intravenosa em bolo de contraste iodado iônico hidrossolúvel $^{7}$, na dose de $1,5 \mathrm{~mL} / \mathrm{kg}$, com exceção de um animal (Cão 1), no qual as condições clínicas contraindicaram a administração do contraste. 0 exame tomográfico de cada animal foi obtido em dois momentos distintos. Um exame inicial foi realizado antes do início do tratamento quimioterápico e um segundo ao término do protocolo quimioterápico instituído. Cada lesão foi avaliada quanto aos seus limites e contornos, atenuação, realce pós-contraste e presença de clivagem com estruturas adjacentes. Para se obter as atenuações em unidades Housfield dos mastocitomas, os exames de tomografia computadorizada nas fases pré e pós foram analisadas em um programa de imagem $^{8}$, onde o perímetro da lesão foi circundado a mão livre por um único operador em todos os cortes transversais obtidos. A partir da demarcação do ROI (region of interest), o sistema forneceu automaticamente a média, desvio padrão, valor mínimo e máximo da atenuação em unidades Housfield (Fig.1). Medidas da atenuação em regiões específicas do tumor também foram aferidas quando necessárias.
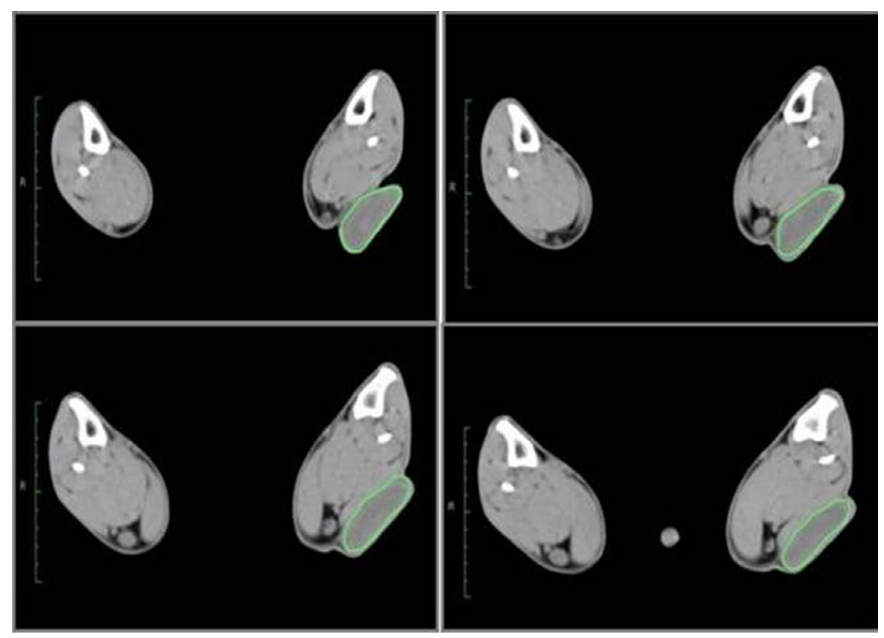

Fig.1. Imagens de tomografia computadorizada, em cortes transversais, janelamento para partes moles, de um mastocitoma grau II localizado em face lateral da tíbia esquerda do cão 15. A formação foi circundada em todos os cortes para se mensurar a atenuação (UH) pelo programa Osirix ${ }^{\circledR}$.

A mensuração unidimensional de cada formação foi realizada com o objetivo de se avaliar a evolução da doença segundo o critério RECIST (Response Evaluation Criteria in Solid Tumors). A partir das imagens tomográficas em cortes transversais selecionou-se o corte onde a lesão alvo era maior, na fase pós-contraste. Neste corte realizou-se a medida do maior diâmetro da lesão, sendo a primeira mensuração obtida antes do início do tratamento quimioterápico e a outra ao término da quimioterapia (Fig.2). A variação

\footnotetext{
${ }^{6}$ Modelo XPRESS/G6, Toshiba

${ }^{7}$ Schering - Urografina 292.

${ }^{8}$ Osirix ${ }^{\circledR}$.
} 


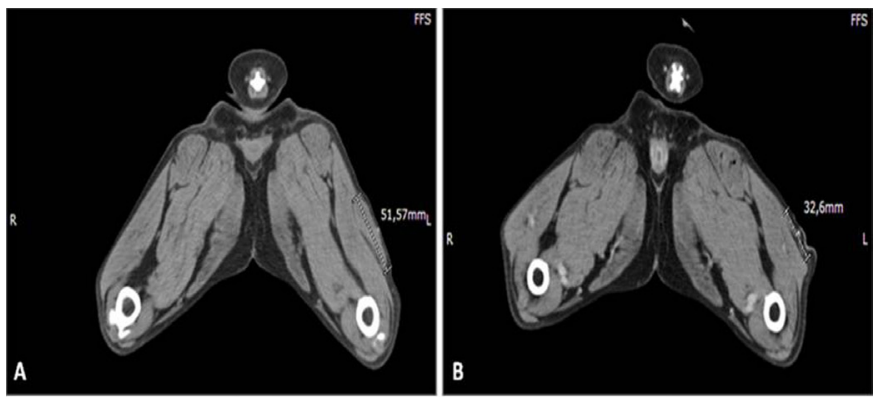

Fig.2. Imagens de tomografia computadorizada, em corte transversal, janelamento para partes moles, de um cão apresentando mastocitoma grau II na face lateral do fêmur do cão 14. (A) Mensuração da lesão em seu maior diâmetro $(5,15 \mathrm{~cm})$, antes do início do tratamento quimioterápico. (B) Mensuração da mesma lesão $(3,26 \mathrm{~cm})$ ao término do tratamento.

Quadro 1. Critérios para a resposta de neoplasias submetidas ao tratamento quimioterápico, segundo RECIST

\begin{tabular}{ll}
\hline \multicolumn{1}{c}{ Resposta } & \multicolumn{1}{c}{ RECIST $^{\mathrm{a}}$} \\
\hline Remissão completa (RC) & Resolução de todas as lesões \\
Remissão parcial (RP) & Redução de pelo menos 30\% do tamanho \\
Doença estável (DE) & $\begin{array}{l}\text { Não segue os critérios nem para RP, nem } \\
\text { para DP }\end{array}$ \\
Doença progressiva (DP) & $\begin{array}{l}\text { Aumento maior que 20\% do tamanho } \\
\text { e/ou aparecimento de novas lesões }\end{array}$ \\
&
\end{tabular}

${ }^{\mathrm{a}}$ RECIST $=$ Response Evaluation Criteria in Solid Tumors; ${ }^{\mathrm{b}}$ Mensurado em seu maior diâmetro. Fonte: Sohaib et al. 2000.

percentual entre as duas mensurações foi calculada e a evolução da doença classificada de acordo com o RECIST (Quadro 1).

Mensurações aferidas nos eixos: dorsoventral, laterolateral/ mediolateral, craniocaudal, dorsopalmar/plantar, rostrocaudal de acordo com a região acometida também foram obtidas a partir das imagens de TC.

0 volume global de cada formação foi aferido por meio do método estereológico conhecido como Princípio de Cavalieri (Fiñana et al. 2003) a partir das imagens tomográficas em cortes transversais pós-contraste, com espessura e incremento conhecidos. Um programa de computador dedicado aferiu o número total de pontos contidos na área da lesão, a partir do qual se estimou o volume das formações (Fig.3). A variação percentual entre as mensurações volumétricas estimadas antes e ao término do tratamento
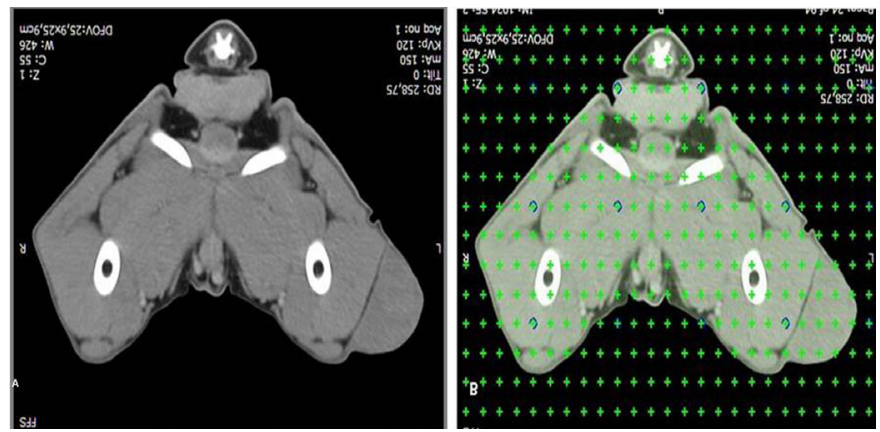

Fig.3. (A) Imagem de tomografia computadorizada, em corte transversal, janelamento para partes moles, de um cão apresentando mastocitoma grau II na face lateral do fêmur esquerdo. (B) A mesma imagem aplicada ao programa que estima o volume pelo Princípio de Cavalieri. 0 número de cruzes contidas na área da lesão foi contado em cada corte para o cálculo do volume global da lesão.

\section{Quadro 2. Critérios para a resposta do tumor submetido ao tratamento quimioterápico, segundo mensuração volumétrica da neoplasia}

\begin{tabular}{ll}
\hline \multicolumn{1}{c}{ Resposta } & \multicolumn{1}{c}{ Volume } \\
\hline Remissão completa (RC) & Resolução de todas as lesões \\
Remissão parcial (RP) & Redução de pelo menos 65\% do volume \\
Doença estável (DE) & Não segue os critérios nem para RP, nem \\
& para DP \\
Doença progressiva (DP) & Aumento maior que 40\% do volume \\
& e/ou aparecimento de novas lesões
\end{tabular}

Fonte: Sohaib et al. 2000.

quimioterápico foi calculada e a evolução da doença classificada de acordo com este método (Quadro 2).

Para as variáveis qualitativas foram determinados valores de frequências absoluta e relativa (\%) e para as quantitativas, valores de média, desvio padrão, coeficiente de variação e valores máximo e mínimo. Com o auxílio do pacote estatístico SPSS v. 15, o coeficiente Kappa e seu respectivo intervalo de confiança de 95\% foram utilizados para analisar a concordância entre os dois métodos de avaliação da resposta tumoral (RECIST e mensuração volumétrica) ao tratamento quimioterápico, obtidos a partir dos exames de tomografia computadorizada.

Este estudo foi aprovado pela Comissão de Ética no Uso de Animais (CEUA) da Faculdade de Medicina Veterinária e Zootecnia da Universidade de São Paulo (Protocolo 2092/2010).

\section{RESULTADOS}

Foram avaliados 19 cães que apresentavam um ou mais de um mastocitoma em diferentes localizações, totalizando 23 lesões neoplásicas.

Desses animais, 8 (42\%) eram machos e 11 (58\%) fêmeas. A idade de acometimento variou de 2 a 12 anos, sendo a média de 7,6 anos (+/- 2,83). Quanto à raça, 5 (27\%) eram Boxer, 3 (16\%) Golden Retriever, 3 (16\%) SRD, 1 (5,125\%) Rottweiler, 1 (5,125\%) Pitbull, 1 (5,125\%) Yorkshire, 1 $(5,125 \%)$ Teckel e $1(5,125 \%)$ Husky Siberiano, 1 (5,125\%) Labrador, 1 (5,125\%) Bulldog e 1 (5,125\%) Bernese Moutain Dog.

Dos 23 mastocitomas, em relação à sua localização, 9 (39\%) mastocitomas encontravam-se situados nos membros, 7 (30\%) no tronco (pescoço, tórax ou abdômen), 5 (22\%) na cabeça, $1(4,5 \%)$ na região perineal e $1(4,5 \%)$ na região genital.

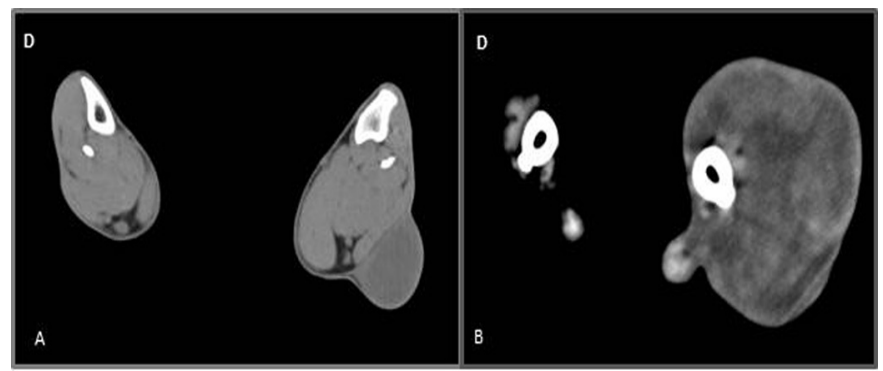

Fig.4. Imagens da tomografia computadorizada de mastocitomas, fase pré-contraste, janelamento para partes moles. (A) Formação de limites definidos, contornos regulares e atenuação homogênea, em face lateral da tíbia esquerda. (B). Formação de limites definidos, contornos regulares e atenuação heterogênea, em face lateral da tíbia esquerda. D: Direito. 
Dezessete mastocitomas (74\%) apresentaram limites bem definidos e $6(26 \%)$ pouco definidos. Apenas três formações apresentaram contornos irregulares (13\%). Quanto à atenuação 9 (39\%) formações apresentaram aspecto heterogêneo, com áreas de permeio hipoatenuantes, hiperatenuantes ou ambas (Fig.4A). As demais formações, ou seja, 14 (61\%) se mostraram de aspecto homogêneo (Fig.4B). Dezesseis lesões $(69,5 \%)$ não apresentaram clivagem com estruturas adjacentes (Fig.5). Sete destas formações $(30,5 \%)$ apresentaram clivagem (Fig.6), embora três delas mostrassem borramento da gordura (Fig.7). Não foram observadas alterações tomográficas ósseas em nenhum caso estudado.
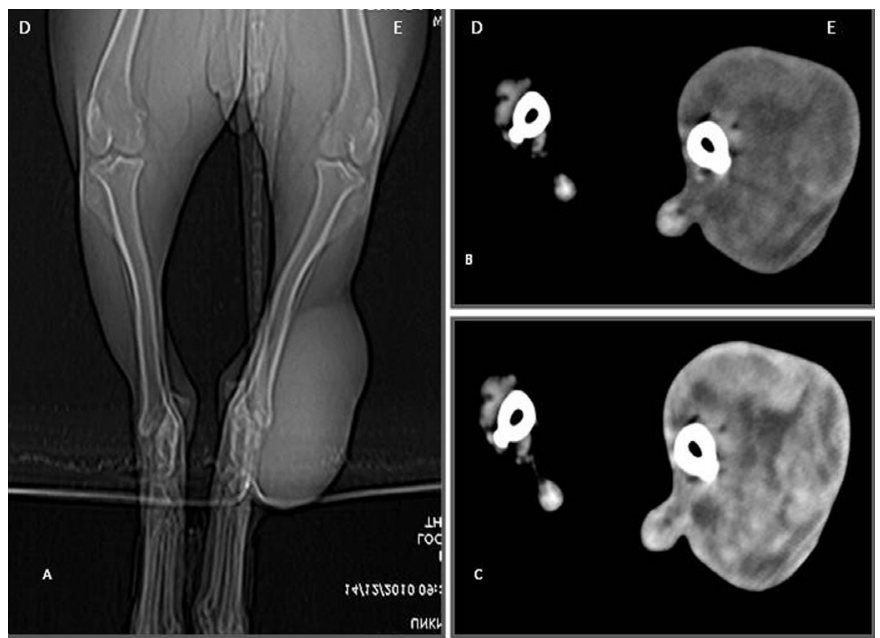

Fig.5. Imagens da tomografia computadorizada do mastocitoma grau II do Cão 3. (A) Radiografia digital, (B) Corte transversal pré-contraste iodado intravenoso e (C) pós-contraste iodado intravenoso. A formação apresenta-se heterogênea e sofre intenso realce também heterogêneo após administração do contraste. Não se observa clivagem com o tecido muscular adjacente. Direito (D). Esquerdo (E).

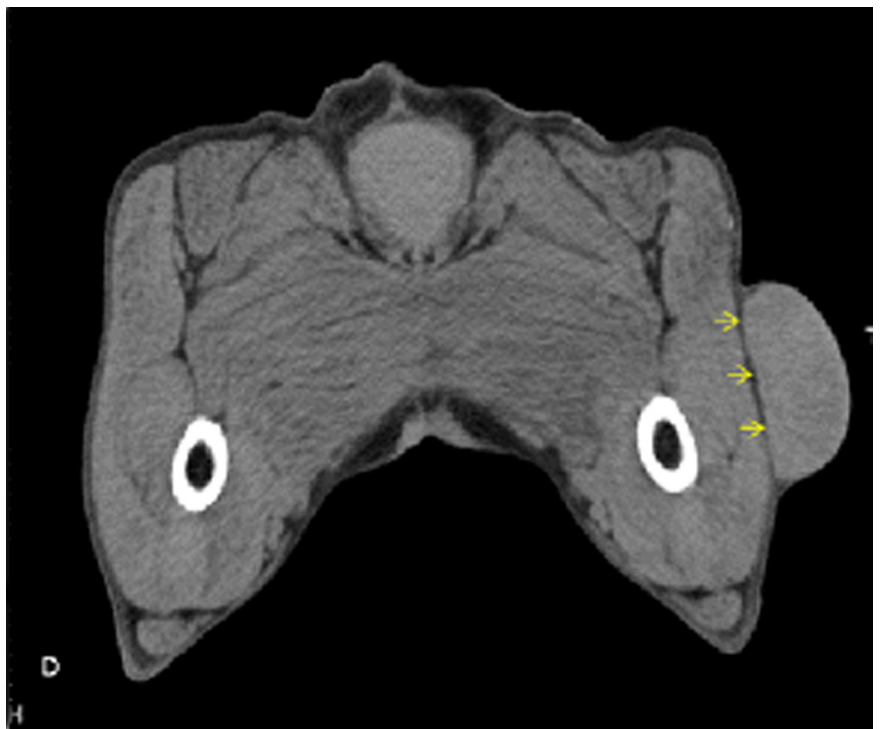

Fig.6. Imagem de tomografia computadorizada, janelamento para partes moles, do mastocitoma grau II do Cão 4, em face lateral do fêmur esquerdo. A formação apresenta linha de clivagem (setas) com o tecido muscular adjacente. Direito (D).

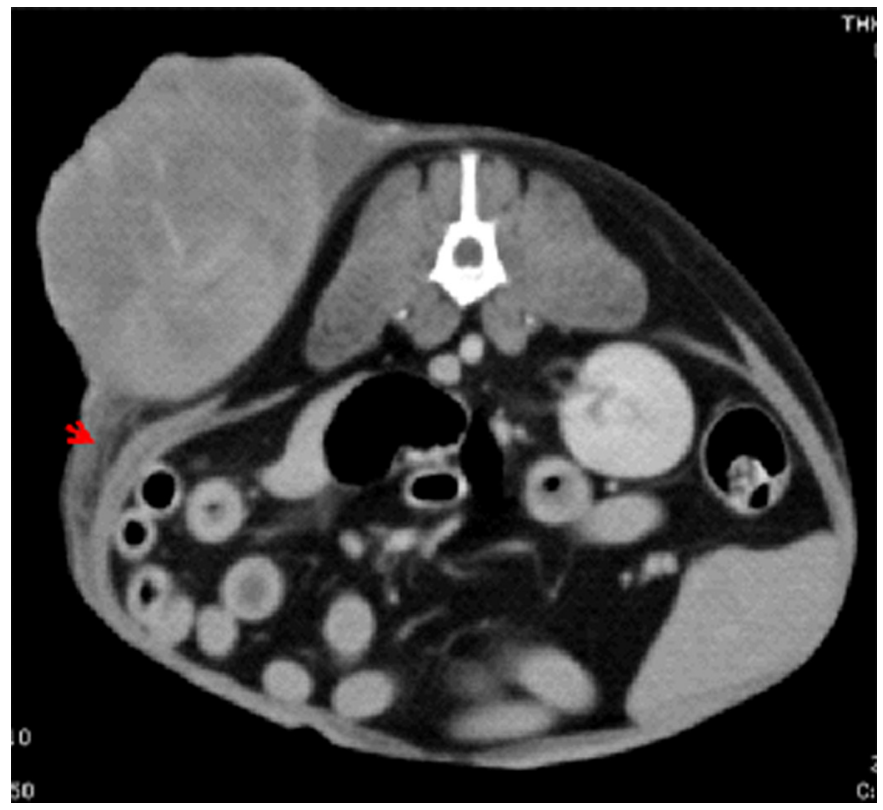

Fig.7. Imagem da tomografia computadorizada, janelamento para partes moles, do mastocitoma grau II do cão 9 em corte transversal pós-contraste iodado intravenoso. A formação apresenta clivagem com a musculatura abdominal adjacente, mas observa-se o borramento da gordura (seta).

0 valor de atenuação dos mastocitomas na fase pré-contraste variou de $18,43 \mathrm{UH}$ a $61,44 \mathrm{UH}$, com média de 37,49 UH (+/-12,41) e coeficiente de variação de $33 \%$. Foram encontrados valor máximo de atenuação de $140 \mathrm{UH}$ e mínimo de -283UH. Após a administração do contraste a atenuação variou de $23,52 \mathrm{UH}$ a $123,15 \mathrm{UH}$, com média de $61,75$ UH (+/- 24,19$)$ e coeficiente de variação de $39 \%$. A variação percentual média da atenuação pré e pós-contraste foi de $64,93 \%(+/-32,25 \%)$ e coeficiente de variação de 49,67\% (Quadro 3).

Visando a avaliação da resposta terapêutica dos tumores submetidos à quimioterapia aplicou-se a cada formação os métodos RECIST (Quadro 4) e a mensuração volumétrica (Quadro 5). Dos 19 cães inclusos, somente em 15 foi possível aplicar a metodologia. Os cães 09, 10, 18 e 19 vieram a óbito durante o tratamento quimioterápico, desta forma, a segunda tomografia computadorizada de controle não foi realizada nestes animais. Esses foram classificados apenas clinicamente como portadores de doença progressiva.

Os quadros 4 e 5 apresentam as mensurações obtidas por meio das duas metodologias e suas respectivas classificações quanto à evolução das formações submetidas ao tratamento quimioterápico. A concordância entre os métodos conduzida por meio do coeficiente kappa (Quadros 6 e 7) mostrou que os métodos RECIST e a mensuração volumétrica apresentaram uma excelente concordância $(\mathrm{K}=0,81)$.

\section{DISCUSSÃO}

Dezenove cães com mastocitoma foram avaliados utilizando-se a tomografia computadorizada. Deste grupo estudado a raça mais acometida foi o Boxer (27\%), descrita como a mais acometida por vários autores (Patnaik et al. 1984, Baker-Gabb et al. 2003, Welle et al. 2008), seguida do Gol- 
Quadro 3. Valores médios de atenuação (unidades Housfield), desvio padrão, valor máximo, mínimo e coeficiente de variação pré e pós-contraste iodado dos mastocitomas avaliados por meio de software Osirix $^{\circledR}$

\begin{tabular}{|c|c|c|c|c|c|c|c|c|c|}
\hline Cão & $\begin{array}{l}\text { Média da } \\
\text { atenuação pré } \\
\text { contraste (UH) }\end{array}$ & $\begin{array}{l}\text { Desvio } \\
\text { padrão }\end{array}$ & $\begin{array}{l}\text { Valor } \\
\text { máximo }\end{array}$ & $\begin{array}{l}\text { Valor } \\
\text { mínimo }\end{array}$ & $\begin{array}{c}\text { Média da } \\
\text { atenuação pós } \\
\text { contraste (UH) }\end{array}$ & $\begin{array}{l}\text { Desvio } \\
\text { padrão }\end{array}$ & $\begin{array}{l}\text { Valor } \\
\text { Max. }\end{array}$ & $\begin{array}{l}\text { Valor } \\
\text { Min. }\end{array}$ & $\Delta \%$ \\
\hline $\mathrm{C} 2$ & 39,38 & 27,67 & 86 & -283 & 46,22 & 14,81 & 97 & -152 & $17,37 \%$ \\
\hline $\mathrm{C} 3$ & 31,18 & 14,18 & 107 & -219 & 50,97 & 23,42 & 134 & -233 & $63,47 \%$ \\
\hline $\mathrm{C} 4$ & 41,72 & 18,13 & 99 & -120 & 77,49 & 18,06 & 134 & -244 & $85,74 \%$ \\
\hline \multirow[t]{3}{*}{$\mathrm{C} 5$} & 50,74 & 10,23 & 89 & -57 & 62,19 & 10,32 & 100 & -31 & $22,57 \%$ \\
\hline & 32,65 & 15,23 & 78 & -47 & 45,68 & 22,02 & 100 & -70 & $39,91 \%$ \\
\hline & 18,43 & 10,22 & 58 & -62 & 23,52 & 18,12 & 78 & -70 & $27,62 \%$ \\
\hline C6 & 21,39 & 37,83 & 99 & -126 & 38,86 & 37,47 & 115 & -112 & $81,67 \%$ \\
\hline C7 & 29,72 & 23,95 & 78 & -212 & 52,28 & 25,73 & 113 & -259 & $75,91 \%$ \\
\hline C8 & 54,31 & 8,44 & 71 & 8 & 123,15 & 13,19 & 175 & 87 & $126,75 \%$ \\
\hline C11 & 25,69 & 14,59 & 68 & -48 & 59,70 & 21,93 & 126 & -114 & $132,39 \%$ \\
\hline C12 & 40,47 & 16,11 & 74 & -68 & 66,90 & 18,53 & 110 & -69 & $65,31 \%$ \\
\hline C13 & 42,25 & 17,17 & 94 & -41 & 69,68 & 21,18 & 136 & 79 & $64,92 \%$ \\
\hline C14 & 27,15 & 22,88 & 82 & -106 & 46,09 & 24,5 & 102 & -81 & $69,76 \%$ \\
\hline C15 & 31,65 & 10,88 & 88 & -34 & 48,56 & 15,26 & 112 & -143 & $53,43 \%$ \\
\hline C16 & 51,70 & 15,36 & 99 & -228 & 79,78 & 27,14 & 206 & -21 & $54,31 \%$ \\
\hline C17 & 61,44 & 16,88 & 140 & -56 & 96,91 & 22,72 & 167 & -193 & $57,73 \%$ \\
\hline
\end{tabular}

$\Delta \%$ = variação percentual média da atenuação pré e pós-contraste.

Quadro 4. Mensurações lineares dos mastocitomas obtidas em seu maior diâmetro a partir do exame de tomografia computadorizada, em corte transversal, e respectiva classificação quanto sua evolução clínica segundo o método RECIST

\begin{tabular}{|c|c|c|c|c|c|c|c|}
\hline Cães & $\begin{array}{l}\text { Localização do } \\
\text { mastocitoma }\end{array}$ & $\begin{array}{l}\text { Mens. pré Qt } \\
\text { (eixos/cm) }\end{array}$ & $\begin{array}{c}\text { Mens. pré QtE } \\
\text { (maior diâmetro } \mathrm{cm} \text { ) }\end{array}$ & $\begin{array}{c}\text { Men. pós } \mathrm{Qt}^{\mathrm{E}} \\
\text { (eixos/cm) }\end{array}$ & $\begin{array}{c}\text { Mens. pós QT } \\
\text { (maior diâmetro } \mathrm{cm} \text { ) }\end{array}$ & $\Delta \%$ & $\begin{array}{l}\text { Classificação } \\
\text { (RECIST) }\end{array}$ \\
\hline \multirow[t]{2}{*}{$\mathrm{C} 1$} & Cervical & $3 \times 2 \times 5,7^{A}$ & 3,25 & $4 \times 2 \times 6$ & 4 & $23,1 \%$ & DP \\
\hline & Tíbia D & $3 \times 2 \times 5,7^{c}$ & 3,75 & $3 \times 3 \times 4$ & 3,75 & $0,0 \%$ & DE \\
\hline $\mathrm{C} 2$ & Toracoabdominal ventral & $6,3 \times 2,4 \times 6,3^{\mathrm{A}}$ & 6,54 & $6,8 \times 2,6 \times 7,5$ & 6,55 & $0,2 \%$ & DE \\
\hline $\mathrm{C} 3$ & Tibiotársica E & $5,6 \times 6 \times 8^{B}$ & 6,11 & $8,7 \times 6 \times 10$ & 8 & $30,9 \%$ & DP \\
\hline $\mathrm{C} 4$ & Fêmur E & $2,7 \times 4,6 \times 6,6^{\mathrm{C}}$ & 4,6 & $3 \times 5,55 \times 6,3$ & 5,55 & $20,7 \%$ & DP \\
\hline \multirow[t]{3}{*}{$\mathrm{C} 5$} & Região peniana & $5,8 \times 3,8 \times 6^{A}$ & 6 & $4,8 \times 3,86 \times 6$ & 4,64 & $-22,7 \%$ & DE \\
\hline & Dorso & $3,4 \times 1,7 \times 3,3^{\mathrm{A}}$ & 3,48 & $0^{*}$ & $0^{*}$ & $-100,0 \%$ & $\mathrm{RC}^{* *}$ \\
\hline & Abdominal ventral & $3 \times 1,3 \times 3,3^{A}$ & 3 & $2,8 \times 1,26 \times 3$ & 2,84 & $-5,3 \%$ & DE \\
\hline C6 & $\begin{array}{l}\text { Região lombar } \\
\text { dorsolateral E }\end{array}$ & $1,6 \times 2,4 \times 4,5^{\mathrm{A}}$ & 3,28 & $1 \times 2,9 \times 2,7$ & 2,79 & $-14,9 \%$ & $\mathrm{DE}$ \\
\hline C7 & $\begin{array}{l}\text { Região abdominal } \\
\text { ventrolateral E }\end{array}$ & $7,7 \times 3,15 \times 18,4^{A}$ & 7,77 & $6,6 \times 2 \times 9,3$ & 6,6 & $-15,1 \%$ & $\mathrm{DE}$ \\
\hline C8 & Plano nasolabial & $0,70 \times 0,5 \times 0,25^{D}$ & 0,75 & $0,75 \times 0,82 \times 0,28$ & 0,86 & $14,7 \%$ & DE \\
\hline $\mathrm{C} 11$ & Abdominal D & $1,5 \times 2 \times 1,5^{A}$ & 2 & $1,6 \times 2,3 \times 3$ & 2,26 & $13,0 \%$ & $\mathrm{DE}$ \\
\hline $\mathrm{C} 12$ & Fêmur E & $1,9 \times 4,13 \times 7,8^{C}$ & 4,13 & $3,5 \times 4,7 \times 9$ & 5 & $21,1 \%$ & DP \\
\hline $\mathrm{C} 13$ & região temporal E & $2,5 \times 7 \times 6^{A}$ & 7,3 & $3,4 \times 8,5 \times 10,8$ & 9 & $23,3 \%$ & DP \\
\hline C14 & Fêmur E & $1.5 \times 5,1 \times 7,2^{\mathrm{C}}$ & 5,28 & $0,35 \times 3 \times 3,9$ & 3 & $-43,2 \%$ & $\mathrm{RP}$ \\
\hline C15 & Tíbia E & $3,53 \times 5,35 \times 2,30^{\mathrm{c}}$ & 5,35 & $2,16 \times 5,75 \times 5,7$ & 5,75 & $7,5 \%$ & DE \\
\hline C16 & Lábio superior E & $6 \times 3,8 \times 4^{\mathrm{D}}$ & 6 & $0^{*}$ & $0^{*}$ & $-100,0 \%$ & $\mathrm{RC}^{* *}$ \\
\hline $\mathrm{C} 17$ & $4^{0}$ dígito MTD & $1,47 \times 1,69 \times 2,4^{\mathrm{B}}$ & 1,69 & $1,0 \times 0,36 \times 1,8$ & 1,0 & $-40,8 \%$ & $\mathrm{RP}$ \\
\hline
\end{tabular}

* Lesões não distinguíveis ao exame tomográfico foram consideradas com valor zero (0). ** 0 exame histopatológico é necessário para confirmar a remissão completa (RC). Mensuração eixos: (laterolateral x dorsoventral x craniocaudal) ${ }^{\mathrm{A}}$; (lateromedial x dorsopalmar/plantar x proximodistal) ${ }^{\mathrm{B}}$; (lateromedial x craniocaudal x proximodistal) ${ }^{\mathrm{C}}$; (laterolateral $\mathrm{x}$ dorsoventral $\mathrm{x}$ rostrocaudal) ${ }^{\mathrm{D}} . \Delta \%$ $($ variação percentual $)=$ mensuração pós $\mathrm{Qt} /$ mensuração pré $\mathrm{Qt})-1$. Mens. = mensuração; $\mathrm{Qt}=$ quimioterapia. $\mathrm{RECIST}=$ Response Evaluation Criteria in Solid Tumors. DE = doença estável; DP = doença progressiva; RP = remissão parcial; RC = remissão completa. $\mathrm{E}$ = esquerdo. $\mathrm{D}$ = direito. $\mathrm{MTD}=$ membro torácico direito.

den retriever (16\%) e de cães sem raça definida (16\%). A idade de acometimento também foi equivalente a reportada na literatura (Patnaik et al. 1984, Baker-Gabb et al. 2003, Dobson \& Scase 2007), sendo a média encontrada de 7,6 anos $(+/-2,38)$. Apenas um cão apresentava dois anos de idade, mostrando que o tumor pode ocorrer também em animais mais jovens (Davis et al. 1992). Quanto à predisposição sexual, este estudo não mostrou predileção, corroborando com informações descritas anteriormente (Patnaik et al. 1984, Baker-Gabb et al. 2003, Bronden et al. 2010).
Diferentemente do reportado por Welle et al. (2008) que refere o tronco como a região mais frequentemente acometida, a maioria dos mastocitomas localizavam-se nos membros (39\%), seguido do tronco (30\%), cabeça (22\%), região genital $(4,5 \%)$ e perineal $(4,5 \%)$. 0 acometimento da região genital e perineal foi similar a reportada por Bronden et al. (2010).

Das vinte e três formações avaliadas nas imagens por tomografia computadorizada, dezessete mastocitomas $(74 \%)$ apresentaram limites bem definidos e $6(26 \%)$ pou- 
Quadro 5. Mensurações volumétricas dos mastocitomas, obtidas a partir do exame de tomografia computadorizada e respectiva classificação quanto sua evolução clínica

\begin{tabular}{lccccc}
\hline Cães & $\begin{array}{c}\text { Localização do } \\
\text { mastocitoma }\end{array}$ & $\begin{array}{c}\text { Volume pré } \\
\text { Qt }(\mathrm{cm} 3)\end{array}$ & $\begin{array}{c}\text { Volume pós } \\
\text { Qt (cm3) }\end{array}$ & $\Delta \%$ & $\begin{array}{c}\text { Classifi- } \\
\text { cação }\end{array}$ \\
\hline C1 & Cervical & 17,89 & 30,96 & $73,0 \%$ & DP \\
& Tíbia D & 19,68 & 18,24 & $-7,3 \%$ & DE \\
C2 & Toracoabdominal & 64,73 & 67,9 & $4,9 \%$ & DE \\
& ventral & & & & \\
C3 & Tibiotársica E & 140,87 & 299,25 & $112,4 \%$ & DP \\
C4 & Fêmur E & 124,87 & 182,664 & $46,3 \%$ & DP \\
C5 & Região peniana & 52,63 & 37,9 & $-28,0 \%$ & DE \\
& Dorso & 11,90 & $0 *$ & $-100,0 \%$ & RC** \\
& Abdominal ventral & 7,35 & 4,16 & $-43,4 \%$ & DE \\
C6 & Região lombar & 9,52 & 5,04 & $-47,1 \%$ & DE \\
& dorsolateral E & & & & \\
C7 & Região abdominal & 118,9 & 42,76 & $-64,0 \%$ & RP \\
& ventrolateral E & & & & \\
C8 & Plano nasolabial & 0,76 & 1,40 & $84,2 \%$ & DP \\
C11 & Região abdominal D & 2,79 & 6,5 & $133,0 \%$ & DP \\
C12 & Fêmur E & 58,14 & 85,04 & $46,3 \%$ & DP \\
C13 & Região temporal E & 47,40 & 124,2 & $162,0 \%$ & DP \\
C14 & Fêmur E & 22,23 & 3,762 & $-83,1 \%$ & RP \\
C15 & Tíbia E & 40,95 & 55,404 & $35,3 \%$ & DE \\
C16 & Lábio superior E & 50,4 & $0 *$ & $-100,0 \%$ & RC** \\
C17 & 40 dígito MTD & 4,38 & 0,6 & $-86,3 \%$ & RP
\end{tabular}

$\Delta \%$ (variação percentual $)=($ volume pós $\mathrm{Qt} /$ volume pré $\mathrm{Qt})-1$. Qt: quimioterapia. $\mathrm{DE}$ = doença estável; $\mathrm{DP}=$ doença progressiva; $\mathrm{RP}=$ remissão parcial; RC = remissão completa. * Lesões não passíveis de mensuração ao exame tomográfico foram consideradas com valor zero. ${ }^{* *} 0$ exame histopatológico é necessário para confirmar a remissão completa $(\mathrm{RC}) . \mathrm{E}=$ esquerdo $. \mathrm{D}=$ direito. $\mathrm{MTD}=$ membro torácico direito.

Quadro 6. Comparação entre os métodos RECIST e mensuração volumétrica para a classificação da evolução da doença nos animais submetidos ao tratamento quimioterápico

\begin{tabular}{lccccc}
\hline \multirow{2}{*}{ RECIST } & \multicolumn{4}{c}{ Mensuração volumétrica } & Total \\
\cline { 2 - 4 } & DE & DP & RC & RP & \\
\hline DE & 5 & 2 & 0 & 0 & 7 \\
DP & 0 & 4 & 0 & 0 & 4 \\
RC & 0 & 0 & 2 & 0 & 2 \\
RP & 0 & 0 & 0 & 2 & 2 \\
Total & 5 & 6 & 2 & 2 & 15
\end{tabular}

$\mathrm{DE}$ = doença estável; $\mathrm{DP}$ = doença progressiva; $\mathrm{RC}$ = emissão completa; $\mathrm{RP}=$ remissão parcial.

Quadro 7. Concordância entre os métodos de avaliação da evolução da doença nos animais submetidos ao tratamento quimioterápico

\begin{tabular}{lcc}
\hline Comparação & kappa & Intervalo de confiança (95\%) \\
\hline Volume & 0,810 & {$[0,563 ; 1,057]$}
\end{tabular}

Valores de referência Kappa teste: pobre k $\leq 0,20$; regular $0,21 \leq \mathrm{k} \leq$ 0,40 ; moderada $0,41 \leq \mathrm{k} \leq 0,60$; boa $0,61 \leq \mathrm{k} \leq 0,80$; excelente $0,81 \leq \mathrm{k}$ $\leq 1,00$. Fonte: Vieira 2010 .

co definidos. Todos os mastocitomas localizados na região labial e/ou no plano nasal mostraram-se como formações de limites pouco definidos. Embora o aspecto morfológico dos mastocitomas seja bastante variável e possa ter aspectos diferentes de acordo com seu grau histológico, Welle et al. (2008) relatam que aqueles localizados na região labial se apresentam com aspecto morfológico mal definido, assemelhando-se a áreas edemaciadas. Ao contrário dos sarcomas de aplicação estudados por Carneiro et al. (2010) e
Zardo et al. (2012), os contornos dos mastocitomas tendem a ser mais regulares e mais delimitados .

Nas imagens por TC os mastocitomas podem apresentar aspecto homogêneo ou heterogêneo (Lorigados et al. 2012). Quanto à atenuação, 61\% das lesões eram homogêneas e 39\% apresentaram aspecto heterogêneo, com áreas de permeio hipoatenuantes, hiperatenuantes ou ambas, na fase pré-contraste. Áreas hipoatenuantes que não realçam mesmo após a administração intravenosa do contraste iodado podem representar focos de necrose tecidual ou áreas císticas (Lorigados et al. 2012). Segundo Stacchiotti et al. (2009) pode ser difícil diferenciar estas duas alterações baseando-se apenas nas imagens por TC. Regiões hiperatenuantes intratumorais podem estar relacionadas a áreas de calcificação, hemorragia ou fibrose. Em alguns mastocitomas áreas hiperatenuantes que sofreram intenso realce após a administração do contraste sugerem nestes casos tecido tumoral viável bem vascularizado.

Por representarem tumores cutâneos, os mastocitomas podem ser palpados e avaliados quanto a sua consistência e aderência a planos profundos, além de mensurados clinicamente. Contudo, a avaliação por tomografia se mostrou mais acurada, especialmente se essas formações se estendem a planos mais profundos. Afirma-se que um tumor apresenta linha de clivagem com os tecidos adjacentes quando se observa um espaçamento, geralmente de atenuação gordura, entre estes. A maioria das lesões (69,5\%) não apresentaram clivagem com estruturas vizinhas. Este é um aspecto bastante importante no delineamento das margens cirúrgicas, toda vez que o procedimento cirúrgico for considerado como tratamento. A margem cirúrgica tem sido considerada um dos critérios para estabelecer o prognóstico para os mastocitomas (Seguin et al. 2001, Thamm \& Vail 2007, Dobson et al. 2002, Michels et al. 2002, Simpson et al. 2004). A obliteração da gordura observado em alguns casos deve ser considerada como suspeita, podendo representar inflamação, neovascularização ou mesmo infiltrado neoplásico para o panículo adiposo (Webb 2000).

Na medicina, valores de atenuação em unidades Housfield para determinados tecidos e fluidos estão bem estabelecidos, como por exemplo, para o músculo ( 50 a $55 \mathrm{UH}$ ), osso (300 a 350UH), gordura $(-80$ a $-120 \mathrm{UH})$, pâncreas (40UH), água (0UH), sangue (55UH), entre outros (Leite, Amaro Jr \& Otaduy 2012). Essa avaliação auxilia na caracterização tecidual e na avaliação de possíveis alterações. Embora tenha se encontrado valores máximo e mínimo de atenuação bastante diferente dentro da mesma formação, a média da atenuação dos mastocitomas na fase pré-contraste foi de 37,49 (UH) com coeficiente de variação de $33 \%$. Na fase pós contraste a média foi de $61,75 \mathrm{UH}$ e coeficiente de variação $39 \%$. A variação percentual da atenuação nas fases pré e pós-contraste foi de 64,93\%, mostrando que essas formações sofrem um realce moderado após a administração do contraste. A angiogênese é uma característica importante e tem sido relacionada com a taxa de crescimento e propensão a disseminação de metástases do tumor (Preziosi et al. 2004). Das 23 lesões observadas, a maioria apresentou realce pós contraste relativamente uniforme e somente $3(8,69 \%)$ mostraram realce periférico 
mais evidente. A utilização de meio de contraste nos exames por tomografia se mostrou fundamental para avaliar a vascularização do tumor, diferenciando, em muitas vezes, um tecido viável de um não viável, auxiliando na coleta de material para biópsia. Infelizmente, para a realização de estudos de perfusão tecidual são necessários equipamentos tomográficos e softwares mais avançados (Kambadakone \& Sahani 2009, Nitzl et al. 2009), os quais não dispomos até o presente momento.

Na medicina muitos esforços têm sido realizados na busca de um método capaz de avaliar a resposta tumoral quando submetidos ao tratamento quimioterápico (Hopper et al. 1996, Sohaib et al. 2000, Suzuki et al. 2008, Choi et al. 2007, Kambadakone \& Sahani 2009, Mariotti 2009, Stacchiotti et al. 2009, D’Ippolito et al. 2011). Indicadores da resposta terapêutica são importantes, especialmente quando novos protocolos são comparados com tratamentos já estabelecidos. A mensuração do tumor é um critério amplamente utilizado para avaliar sua evolução e o continua sendo o método preconizado na clínica oncológica, apesar de ter sofrido algumas modificações e apresentar limitações. Alguns estudos demostram que tumores que estão respondendo ao tratamento quimioterápico paradoxalmente podem aumentar de tamanho e volume, devido ao aumento da inflamação e áreas de necrose tecidual (Choi et al. 2007, Stacchiotti et al. 2009). Outros pesquisadores afirmam que se a variação percentual na medida do maior diâmetro do tumor não reflete as mudanças nas outras dimensões, então aferir o volume seria mais acurado (Sohaib et al. 2000). Neste estudo quando se comparou a resposta tumoral por meio do RECIST e do volume houve uma boa concordância entre os métodos, resultado semelhante foi observado por Sohaib et al. (2000) ao estudarem 16 pacientes com tumores de células germinativas e linfomas submetidos à quimioterapia. Apenas em três cães a resposta foi diferente entre os dois critérios. 0 mastocitoma do cão 7 apresentou DE pelo RECIST e RP pelo volume. Ao observarmos as medidas aferidas no seu eixo craniocaudal a lesão diminuiu praticamente à metade. A neoplasia do cão 11 foi classificada como DE pelo RECIST e DP pelo volume. Essa lesão dobrou de tamanho em seu eixo craniocaudal. 0 mastocitoma do cão 8 foi classificado como DE pelo RECIST e DP pelo volume. Esse tumor aumentou de tamanho em todos os seus eixos. Estes representaram casos em que a dimensão do maior diâmetro da lesão não refletiu as alterações nas outras dimensões, representado aqui principalmente pelo seu eixo craniocaudal.

Do ponto de vista operacional o RECIST se mostrou uma técnica de fácil execução, reproduzível e que consome pouco tempo do observador. Neste estudo, o volume foi aferido pelo Princípio de Cavalieri, método muito utilizado em estereologia e considerado imparcial, ou seja, capaz de estimar o volume independentemente da forma do objeto em estudo (Fiñana et al. 2003). Devido aos mastocitomas apresentarem formatos bastante variáveis optou-se por esta metodologia. Contudo, para sua realização um software dedicado e a utilização de fórmulas no cálculo do volume foram necessários. Atualmente, softwares são capazes de realizar o cálculo do volume de tumores a partir da somatória das áreas das lesões demarcadas nos cortes transversais.

\section{CONCLUSÕES}

Ao exame por tomografia computadorizada os mastocitomas representaram formações com aspectos diferentes quanto a sua atenuação, podendo ser homogêneos ou heterogêneos, mas com tendência a limites mais definidos e contornos regulares e apresentaram realce moderado após administração do contraste iodado intravenoso.

0 exame se mostrou bastante útil na delimitação do tumor e, consequentemente, no planejamento das margens cirúrgicas.

0 método RECIST aplicado às imagens por tomografia computadorizada é um método reproduzível, de execução relativamente rápida, sendo um método que pode fornecer um parâmetro da resposta ao tratamento instituído.

O RECIST e a mensuração volumétrica apresentaram uma boa correlação quanto à classificação da resposta dos mastocitomas submetidos à quimioterapia.

Contudo, para lesões mais alongadas a estimativa do volume por meio da Estereologia (Princípio de Cavalieri) se mostrou mais eficiente.

Agradecimentos.- À FAPESP-Fundação de Amparo à Pesquisa do Estado de São Paulo, pelo auxílio à pesquisa n 2009/02359-0.

\section{REFERÊNCIAS}

Baker-Gabb M., Hunt G.B. \& France M.P. 2003. Soft tissue sarcomas and mast cell tumours in dogs, clinical behaviour and response to surgery. Aust. Vet. J. 81:732-738.

Bronden L.B., Eriksen T. \& Kristensen A.T. 2010. Mast cell tumours and other skin neoplasia in Danish dogs - data from the Danish Veterinary Cancer Registry. Acta Vet. Scand. 52:1-6.

Carneiro C.S., Pinto A.C.C.B.F. \& Matera J.M. 2010. Computed tomography characterization of feline injection-site sarcomas in 17 cases. Anais European Veterinary Diagnostic Imaging, Annual Scientific Conference, Justus-Liebig-Universität Giessen, p.29. (Resumo)

Choi H., Charnsangavej C., Faria S.C., Macapinlac H.A., Burgess M.A., Paterl S.R., Podoloff D.A. \& Benjamin R.S. 2007. Correlation of computed tomography and positron emission tomography in patients with metastatic gastrointestinal stromal tumor treated at a single institution with imatinib mesylate: proposal of new computed tomography response criteria. J. Clin. Oncol. 25:1753-1760.

Davis B.J., Page R., Sannes P.L. \& Meuten D.J. 1992. Cutaneous mastocytosis in a dog. Vet. Pathol. 29:363-365.

D'Ippolito G., Torres L.R., Saito Filho C.F. \& Ferreira R.M. 2011. CT and MRI in monitoring response: state-of-the-art and future developments. Quart.. J. Nucl. Med. Mol. Imaging 55:603-619.

Dobson J.M., Samuel S., Milstein H., Rogers K. \& Wood J.L. 2002. Canine neoplasia in the UK. Estimates of incidence rates from a population of insured dogs. J. Small Anim. Pract. 43:240-246.

Dobson J.M. \& Scase T.J. 2007. Advances in the diagnosis and management of cutaneous mast cell tumours in dogs. J. Small Anim. Pract. 48:424-431.

Elston L.B., Sueiro F.A., Cavalcanti J.N. \& Metze K. 2009. The importance of the mitotic index as a prognostic factor for survival of canine cutaneous mast cell tumors: a validation study. Vet. Pathol. 46:362-365.

Fiñana M.G., Orive L.M., Mackay C.E., Pakkenberg B. \& Roberts N. 2003. Comparison of MR imaging against physical sectioning to estimate the volume of human cerebral compartments. Neuroimage 18:505-516.

Hopper K.D., Kasales C.J., Eggli K.D., Tenhave T.R., Belman N.M. \& Potok P.S. 1996. The impact of $2 \mathrm{D}$ versus 3D quantitation of tumor bulk dtermination on current methods of assessing response to treatment. J. Comput. Assist. Tomogr. 20:930-37.

Kambadakone A.R. \& Sahani D.V. 2009. Body perfusion CT: technique, clinical applications, and advances. Radiol. Clin. North Am. 47:161-178. 
Leite C.C., Amaro Jr R.E. \& Otaduy M.G. 2012. Física básica da tomografia computadorizada.2006.Disponível em <http://www.hcnetusp.br/ inrad/departamento/graduação/aula/Fisica\%20basica\%da\%20tomografia\%20computadorizada.doc> Acesso em 20 nov. 2012.

Lorigados C.A.B., Matera J.M., Macedo T. \& Pinto A.C.B.C.F. 2012. Avaliação por tomografia computadorizada dos mastocitomas. Vet. Zootec. 19 (Supl 3):10-12.

Macy D.W. 1986. Canine and feline mast cell tumors: biologic behavior, diagnosis, and therapy. Semin. Vet. Med. Surg. Small Anim. 1:72-83.

Maglennon G.A., Murphy S., Adams V., Miller J., Smith K., Blunden A. \& Scase T.J. 2008. Association of Ki67 index with prognosis for intermediategrade canine cutaneous mast cell tumours. Vet. Comp. Oncol. 6:268-274.

Mariotti M. 2009. Por que revisar os critérios de resposta em tumores sólidos? Revta Assoc. Méd. Bras. 55:369-371.

Merlo D.F., Rossi L., Pellegrino C., Ceppi M., Cardellino U., Capurro C., Ratto A., Sambucco P.L., Sestito V., Tanara G. \& Bocchini V. 2008. Cancer incidence in pet dogs: findings of the animal tumor registry of Genoa, Italy. J. Vet. Intern. Med. 22:976-984.

Michels G.M., Knapp D.W., Denicola D.B., Glickman N. \& Bonney P. 2002. Prognosis following surgical excision of canine cutaneous mast cell tumors with histopathologically tumor-free versus nontumor-free margins: a retrospective study of 31 cases. J. Am. Anim. Hosp. Assoc. 38:458-466.

Nitzl D., Ohlerth S., Schwandt F.M., Angst A., Roos M. \& Hotz B.K. 2009. Dynamic computed tomography to measure tissue perfusion in spontaneous canine tumors. Vet. Radiol. Ultrasound 50:347-352.

Patnaik A.K., Ehler W.J. \& MacCewen E.G. 1984. Canine cutaneous mast cell tumor: morphologic grading and survival time in 83 dogs. Vet. Pathol. 21:469-474.

Preziosi R., Sarli G. \& Paltrinieri M. 2004. Prognostic value of intratumoral vessel density in cutaneous mast cell tumors of the dog. J. Comp. Pathol. 130:143-151.

Rothwell T.L., Howlett C.R., Middleton D.J., Griffiths D.A. \& Duff B.C. 1987. Skin neoplasms of dogs in Sydney. Aust. Vet. J. 64:161-164.

Scase T.J., Edwards D., Miller J., Henley W., Smith K., Blunden A. \& Murphy S. 2006. Canine mast cell tumors: correlation of apoptosis and proliferation markers with prognosis. J. Vet. Intern. Med. 20:151-158.

Seguin B., Faulkner B.M. \& McCallan J.L. 2001. Recurrence rate, clinical out- come, and cellular proliferation indices as prognostic indicators after incomplete surgical excision of cutaneous grade II mast cell tumors: 28 dogs (1994-2002). J. Vet. Intern. Med. 20:933-940.

Sfiligoi G., Rassnick K.M., Scarlett J.M., Northrup N.C. \& Gieger T.L. 2005. Outcome of dogs with mast cell tumors in the inguinal or perineal region versus other cutaneous locations: 124 cases (1990-2001). J. Am. Vet. Med. Assoc. 226:1368-1374.

Simpson A.M., Ludwig L.L., Newman S.J., Bergman P.J., Hottinger H.A. \& Patnaik A.K. 2004. Evaluation of surgical margins required for complete excision of cutaneous mast cell tumors in dogs. J. Am. Vet. Med. Assoc. 224:236-240.

Sohaib S.A., Tuner B., Hanson J.A., Farquharson M., Oliver R.T.D. \& Reznek R.H. 2000. CT assessment of tumour response to treatment: comparison of linear, cross-sectional and volumetric measures of tumour size. Brit. J. Radiol. 73:1178-1184.

Stacchiotti S., Collini P., Messina A., Morosi C., Barisella M. \& Bertulli R. 2009. High grade soft tissue sarcomas: tumor response assessment: pilot study to assess the correlation between radiology and pathologic response by using RECIST and Choi criteria. Radiology 25:447-456.

Suzuki C., Jacobsson H., Hatschet T., Torkzad H., Bode'n K., Eriksson-Alm Y., Berg E. \& Blomavist L. 2008. Radiologic measurements of tumor response to treatment: practical approaches and limitations. Radiographics 28:329-344.

Thamm D.H. \& Vail D.M. 2007. Mast cell tumors, p.402-424. In: Withrow S.J. (Ed.), Small Animal Clinical Oncology. $4^{\text {th }}$ ed. Saunders Elsevier, St Louis.

Thompson J.J., Pearl D.L., Yager J.A., Best S.J., Coomber B.L. \& Foster R.A. 2011. Canine subcutaneous mast cell tumor: characterization and prognostic indices. Vet. Pathol. 48:156-168.

Vieira S. 2010. Bioestatística: tópicos avançados. Elsevier, Rio de Janeiro, p.199-220.

Webb W.R. 2000. Mediastino-anormalidades linfonodais e massas tumorais, p.34-60. In: Ibid. (Ed.), Tomografia Computadorizada do Corpo. Editora Guanabara Koogan, Rio de Janeiro.

Zardo K.M., Fonseca Pinto A.C.B.C., Carneiro C.S., Matera J.M., Sendyk-Grunkraut A. \& Lorigados C.A.B. 2012 Aspectos tomográficos do sarcoma de aplicação felino. Anais II SINDIV, Curitiba, PR. (Resumo) 